\title{
Analysis of new Gleeble tensile specimen design for hot stamping application
}

\author{
Manikandan Ganapathy ${ }^{1}$, Nan Li ${ }^{1, a}$, Jianguo Lin ${ }^{1}$, Michael Abspoel ${ }^{2}$, Hensen Guido ${ }^{2}$, and Debashish \\ Bhattacharjee $^{2}$ \\ ${ }^{1}$ Mechanics of Materials, Department of Mechanical Engineering, Imperial College London, London \\ SW7 2AZ, UK \\ ${ }^{2}$ Research \& Development, Tata Steel, IJmuiden, The Netherlands
}

\begin{abstract}
Hot tensile testing is useful to understand the material behavior at elevated temperatures. Hence it is of utmost importance that the test condition is accurate enough to derive stress-strain data in fully austenitic state and to ensure homogeneous deformation throughout the gauge length of the specimen. But present limitation of standard Gleeble hot tensile sample geometry could not be used to achieve a uniform temperature distribution along the gauge section, thus creating errors of experimental data. In order to understand the effect of sample geometry on temperature gradient within the gauge section coupled electrical-thermal and thermo-mechanical finite element analysis has been carried out using Abaqus, with the use of viscoplastic damage constitutive equations presented by $\mathrm{Li}$ [1]. Based on the experimental study and numerical analysis, it was observed that the new sample geometry introduced by Abspoel [2], is able to achieve a better uniformity in temperature distribution along the gauge length; The temperature deviation along the gauge length within $25^{\circ} \mathrm{C}$ during soaking and $5^{\circ} \mathrm{C}$ after cooling and onset of deformation); also the strain deformation is found to be almost homogeneous.
\end{abstract}

\section{Introduction}

Hot stamping processes become more popular for stamping ultra-high strength engineering components for automotive and other applications for weight reduction or safety reasons. The ductility and stressstrain curves are the primary data for assessing the properties of materials in hot stamping conditions. In FE analysis, accurate true stress-strain curves for a range of temperatures and strain rates covering the working conditions are also required. In general, true stress-strain behaviour of the material in hot stamping conditions is experimentally replicated with the help of a Gleeble thermo-mechanical simulator. In order to describe the material behaviour more precisely in finite element analysis, unified viscoplastic damage constitutive equations have been developed and implemented into finite element calculations by Lin [3]. The effective execution of good material model also depends on the accuracy of experimental data. In practical test conditions, the specimen temperature is not uniform along the

\footnotetext{
${ }^{\text {a }}$ Corresponding author: n.li09@imperial.ac.uk
}

This is an Open Access article distributed under the terms of the Creative Commons Attribution License 4.0, which permits unrestricted use, distribution, and reproduction in any medium, provided the original work is properly cited. 

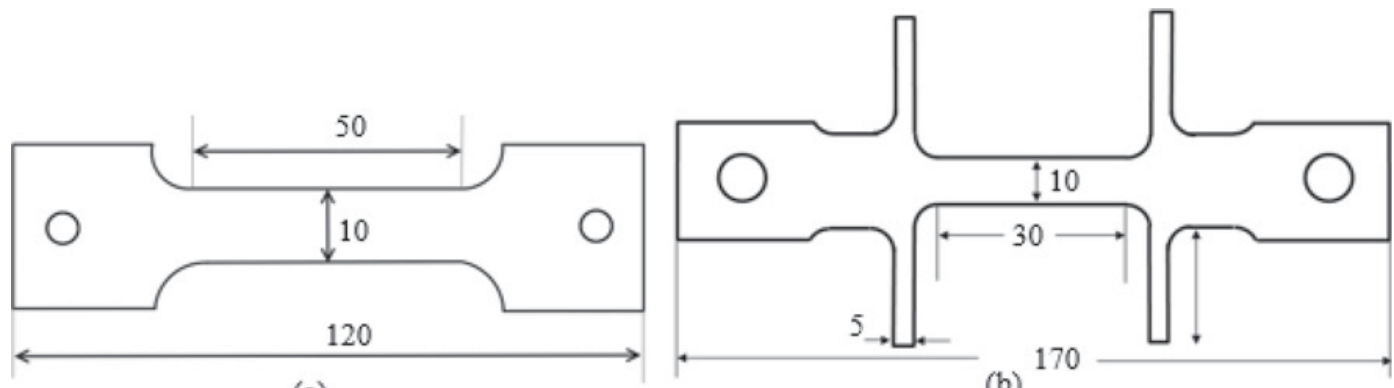

(a)

(b)

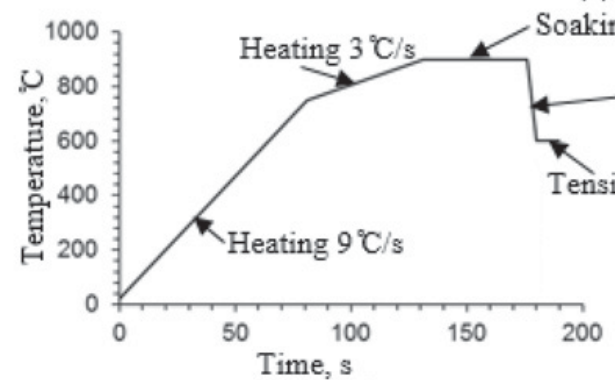

(c)

Figure 1. Specimen designs for a) a standard sample, b) a new sample [2], and c) designed testing temperature profile.

gauge length due to constraints imposed by electrical resistance heating method and heat loss at the ends through the grips.

If the deformation is performed at these large temperature gradients, then there is a chance that the centre of the specimen is at austenitic state and the sides of the sample remain in ferrite state. The ferrite can be softer than the austenite for a certain temperature range [4]. Straining the sample causes strain concentration on the softer ferrite and fracture will occur away from the centre of the specimen along with heterogeneous deformation. To overcome the above limitations in attaining uniform temperature distribution and homogeneous deformation for longer gauge length $(30 \mathrm{~mm})$, a new sample geometry has been used by Abspoel [2]. To understand the influence of the sample geometry on temperature gradients and its consequences in material deformation in Gleeble thermo-mechanical simulator a coupled electrical-thermal-mechanical analysis was performed using ABAQUS for both standard and the sample geometry as proposed by Abspoel et al. [2] and results were discussed in detail.

\section{Experimental details}

Hot tensile tests were performed in Gleeble 3800 for both new and standard sample geometry. The sample geometries are shown in Fig. 1(a) and (b). The material considered for this study is zinc coated boron steel. The material was heated up to $750^{\circ} \mathrm{C}$ at a heating rate of $9{ }^{\circ} \mathrm{C} / \mathrm{s}$ followed by a slow heating rate of $3{ }^{\circ} \mathrm{C} / \mathrm{s}$ up to $900^{\circ} \mathrm{C}$ and held at $900^{\circ} \mathrm{C}$ for 45 Seconds for austenisation and homogenization, then air-cooled to the deformation temperature of $600^{\circ} \mathrm{C}$ as shown in Fig. 1(c).

The test setup for the new testpiece design (Fig. 1(b)) in the Gleeble chamber is shown in Fig. 2(a) and the current flow direction for heating the testpiece is shown in Fig. 2(b). Throughout the test, the temperature was monitored at three different positions along the specimen gauge length using thermocouples TC1 (centre), TC2 (5 mm from centre) and TC3 (15 mm from centre) as shown in Fig. 2(c). The objective of the proposed new sample geometry by Abspoel [2] was to achieve a uniform temperature 


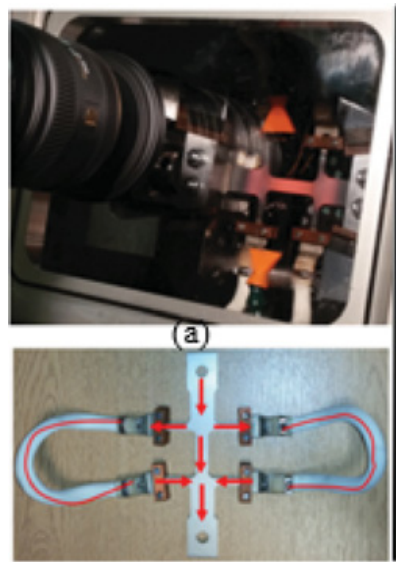

(b)

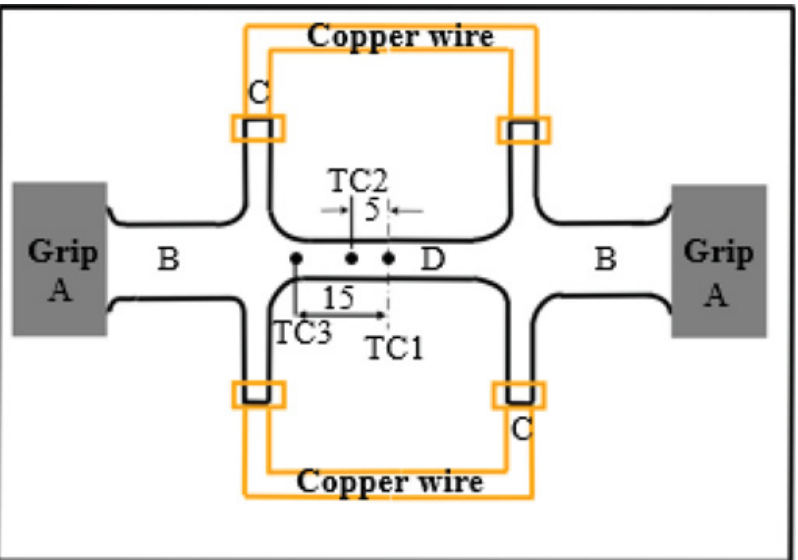

(c)

Figure 2. Hot tensile test using the new specimen design. a) Test Setup; b) current flow: c) Gleeble test gripping conditions.

distribution along the gauge length by creating a buffer to the heat loss to the water cooled grips with a supplementary region between the gauge section and the shoulders, so that the gauge section is insulated from the cooled stainless steel grips. Shoulder (A), Supplementary region (B), shunt arrangement with copper braid wire (C) and gauge section (D) are shown in the Fig. 2(c). In order to realize sufficient heat generation in the supplementary heating sections, the electric current density in these sections was made equal to that in the gauge section by a shunt resistance parallel to the gauge section. The shunt strips at both ends of the gauge section are connected by a flexible braided copper cable, fixed to the strips by copper clamps.

\section{Finite Element modeling procedures}

The Finite Element modelling process comprises two steps. The first step of analysis is a coupled electrical-thermal finite element simulation using ABAQUS through the user defined feedback control subroutine, UAMP. The second part is coupled thermo-mechanical simulation with the use of a set of unified viscoplastic damage material model, through VUMAT, to study the deformation behaviour.

\subsection{Coupled electrical-thermal analysis}

In the first step, Abaqus/Implicit coupled electrical-thermal analysis was conducted for simulating the heating and cooling of the steel sample, at specified heating and cooling rates. Due to the symmetric feature of the testpiece design and the current flow, only quarter of the set-up is simulated, which is shown in Fig. 3. Temperature dependent material properties were considered for both stainless steel grips and the boron steel specimen, which are defined in [5]. The heat loss to the grip by conduction and heat loss to atmosphere by convection were considered in this analysis. The specimens and grips were discretized with 8-node linear coupled thermal-electric brick elements. To capture the thermal and mechanical gradients in the gauge section of the specimen, fine plane stress elements were generated in gauge section with the element size of $0.5 \mathrm{~mm}$. The heating rate of the boron steel sample is controlled by electrical current input, which is controlled by the user-defined subroutine, UAMP. The FE simulated temperature, as recorded from N1 (TC1), is then compared with the prescribed temperature as described 
Table 1. Coefficient $\alpha$ used in the UAMP subroutine to achieve the replication of the prescribed heating cycle.

\begin{tabular}{cccccc}
\hline interval & Heating1 & Heating2 & Soaking & Cooling & Testing \\
\hline Standard sample & 0.15 & 0.13 & 0.13 & 0.02 & 0.2 \\
\hline New sample & 0.4 & 0.3 & 0.3 & 0.02 & 0.2 \\
\hline
\end{tabular}

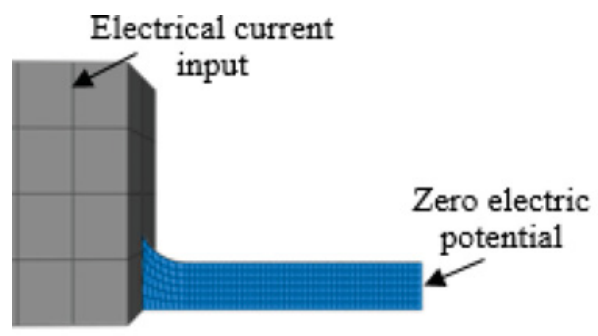

(a)

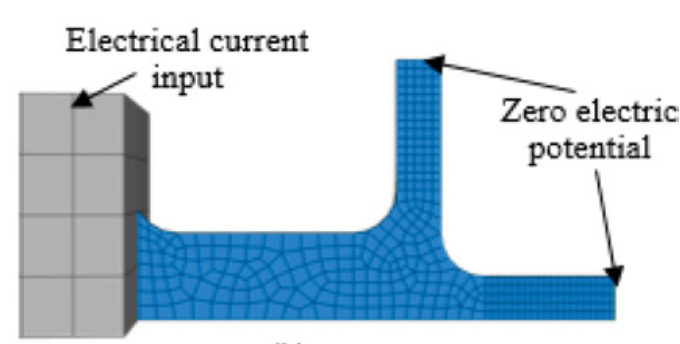

(b)

Figure 3. FE models of hot tensile test for (a) standard testpiece geometry; (b) new sample geometry.

using Eq. (1), which was detailed in [6].

$$
\Delta T_{i}=T_{i}^{p}-T_{i}^{s} ; \quad \Delta I=\left(1+\frac{\Delta T_{i}}{T_{i}^{p}}\right)^{\alpha} \pm \beta \quad \text { and } \quad I_{i}=I_{i-1} * \Delta I .
$$

$T_{i}^{p}$ and $T_{i}^{s}$ are the prescribed and measured temperatures at $i^{\text {th }}$ time increment, $\alpha$ is a coefficient that remains constant according to the corresponding time interval as shown in Table 1 and $\beta$ is a constant coefficient, where $\beta$ is 0.001 . The correction term, $\Delta I$, is then multiplied by the current used $\left(I_{i-1}\right)$ in the previous time increment.

\subsection{Coupled thermo-mechanical analysis}

In the second step, Abaqus/Explicit coupled thermal-mechanical analysis was performed using equation set (2), which was input into the solver through the user defined subroutine, VUMAT. The viscoplastic damage constitutive Eq. (2) for the boron steel under hot stamping conditions were determined by Li [1]. The temperature profile on the specimen calculated from the previous time increment of electricalthermal analysis was used for deformation analysis.

$$
\begin{aligned}
& \dot{\varepsilon}^{p}=\dot{\varepsilon}^{\mathrm{o}}\left[\frac{\left|\frac{\sigma}{1-\omega}\right|-\mathrm{k}-H}{\mathrm{~K}}\right]^{\mathrm{n}_{\mathrm{v}}} \frac{1}{(1-\omega)^{\gamma_{1}}} ; \text { If }\left|\frac{\sigma}{1-\omega}\right|-\mathrm{k}-H \leq 0, \dot{\varepsilon}^{p}=0, \text { If } \dot{\varepsilon}^{o}=1(\sigma>0), \\
& \text { If } \dot{\varepsilon}^{o}=-1(\sigma<0) \\
& H=\mathrm{B} \bar{\rho}^{\mathrm{n}_{\mathrm{R}}} ; \dot{\bar{\rho}}=\left.A(1-\bar{\rho})\right|_{\dot{\varepsilon}} ^{p} \mid-\mathrm{C} \bar{\rho}^{\gamma_{1}} ; \dot{\omega}=\beta \frac{\sigma^{\gamma_{3}}\left|\dot{\varepsilon}^{p}\right|}{(1-\omega)^{\varphi}} ; \text { and } \sigma=\mathrm{E}(1-\omega)\left(\varepsilon^{T}-\varepsilon^{P}\right) .
\end{aligned}
$$

The temperature dependent constitutive equations used for the analysis are summarised in equation set (2). The determined constants for the boron steel are listed in Table 2. The description of the equations for temperature dependent material constants are detailed in equation set (3).

$$
\begin{aligned}
& k=k_{0} \exp \left(\frac{Q}{R T}\right) ; K=K_{0} \exp \left(\frac{Q}{R T}\right) ; n_{v}=n_{v 0} \exp \left(\frac{Q_{n}}{R T}\right) ; B=B_{0} \exp \left(\frac{Q_{B}}{R T}\right) ; \\
& C=C_{0} \exp \left(-\frac{Q_{C}}{R T}\right) ; \beta=\beta_{0} \exp \left(\frac{Q_{\beta}}{R T}\right) ; E=E_{0} \exp \left(\frac{Q_{E}}{R T}\right) .
\end{aligned}
$$


Table 2. Material constants for the austenite phase of boron steels [1].

\begin{tabular}{|c|c|c|c|c|c|c|c|c|c|}
\hline $\begin{array}{c}\mathbf{Q} \\
(\mathrm{J} / \mathrm{mol})\end{array}$ & $\begin{array}{c}\text { Qn } \\
(\mathrm{J} / \mathrm{mol})\end{array}$ & $\begin{array}{c}\text { QC } \\
(\mathrm{J} / \mathrm{mol})\end{array}$ & $\begin{array}{c}\mathrm{QB} \\
(\mathrm{J} / \mathrm{mol})\end{array}$ & $\begin{array}{c}\mathrm{QE} \\
(\mathrm{J} / \mathrm{mol})\end{array}$ & $\begin{array}{c}Q \beta \\
(\mathrm{J} / \mathrm{mol})\end{array}$ & $\begin{array}{c}\mathbf{k}_{\mathbf{0}} \\
(\mathrm{MPa})\end{array}$ & $\mathbf{A}$ & $\begin{array}{c}\mathbf{B}_{0} \\
(\mathrm{MPa})\end{array}$ & $\mathrm{C}_{0}$ \\
\hline 4000 & 50000 & 10000 & 24000 & 1400 & 8000 & 12.921 & 16 & 12.084 & 0.56 \\
\hline $\begin{array}{c}\mathbf{E}_{0} \\
(\mathrm{MPa})\end{array}$ & $\begin{array}{c}\mathbf{K}_{0} \\
(\mathrm{MPa})\end{array}$ & $\begin{array}{c}\mathbf{R} \\
(\mathrm{J} / \mathrm{mol} . \mathrm{K})\end{array}$ & $\varphi$ & $\mathbf{n}_{\mathrm{v} 0}$ & $\mathbf{n}_{\mathbf{R}}$ & $\gamma_{1}$ & $\gamma_{2}$ & $\gamma_{3}$ & $\begin{array}{c}\boldsymbol{\beta}_{\mathbf{0}} \\
\left(\mathrm{MPa}_{\mathbf{3}}^{-\gamma}\right)\end{array}$ \\
\hline 143800 & 31.354 & 8.314 & 10.5 & 0.0185 & 0.4 & 3.4 & 1.55 & 0.5 & $5.996 \mathrm{e}-3$ \\
\hline
\end{tabular}

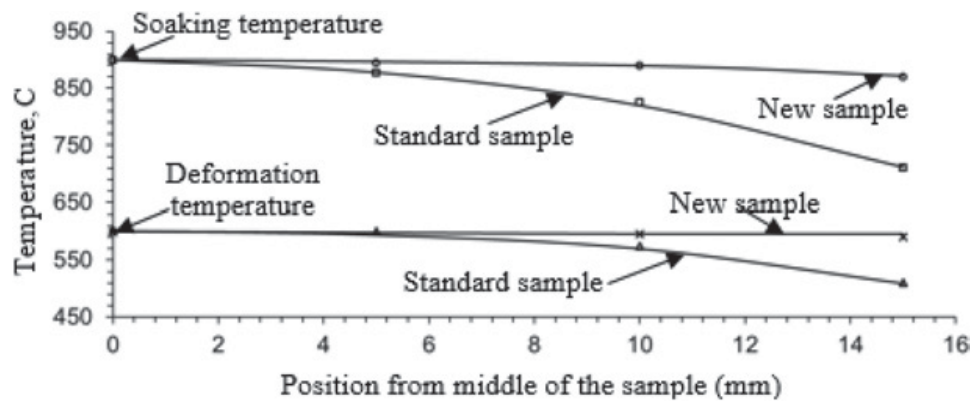

Figure 4. Comparison of experimental (symbols) and computed (solid curves) temperature distributions along the gauge length for the two specimen designs.

Where $\mathrm{R}$ is the gas constant and $\mathrm{T}$ is the absolute temperature. $\mathrm{Q}, \mathrm{Q}_{\mathrm{n}}, \mathrm{Q}_{\mathrm{B}}, \mathrm{Q}_{\mathrm{C}}, \mathrm{Q}_{\beta}, \mathrm{Q}_{\mathrm{E}}, \mathrm{k}_{0}, \mathrm{~A}, \mathrm{~B}_{0}, \mathrm{C}_{0}$, $\beta_{0}, \mathrm{~K}_{0}, \mathrm{n}_{v 0}, \varphi, \gamma_{1}, \gamma_{2}$ and $\gamma_{3}$ are constants.

\section{Results and discussion}

\subsection{Coupled electrical-thermal analysis}

Figure 4 shows the measured and FE predicted temperature profiles along the gauge section at the end of the soaking and the starting of the deformation for the two specimens. The FE predicted results agree well with that from the experimentation. It can be seen from Fig. 4 that the temperature variation along the gauge section of standard testpiece during soaking is $190^{\circ} \mathrm{C}$ and onset of deformation is $90{ }^{\circ} \mathrm{C}$. But in case of new sample design the temperature deviation during soaking is within $25^{\circ} \mathrm{C}$ and during deformation is within $5^{\circ} \mathrm{C}$. Figure 5 shows the temperature gradient along the gauge length. For in the standard specimen, shown in Fig. 5(a), the gauge section is highly affected by the water-cooled grip leading to a large temperature gradient over the gauge length. In the case of new sample design (Fig. 5(b)) the gauge section is isolated from the grip by a supplementary region, so the temperature gradient within the gauge length is negligible in newly designed specimen. Figure 6 shows the temperature gradient at the onset of deformation. It can be seen from Fig. 6(b) that even after cooling, the supplementary region is hotter than the gauge area. The heat extracted by the grip is supplied by supplementary region, thus the temperature in the gauge section remains uniform.

\subsection{Coupled thermo-mechanical analysis}

Figure 7(a) shows the axial stress-strain curves calculated from the central element for both the standard and new samples deformed at $600^{\circ} \mathrm{C}$ with the strain rate of 1/s. Figure 7(b) shows the axial strain along the gauge length at various time intervals. Failure was detected at central element for a damage value of 0.7. The times at failure $\left(\mathrm{t}_{\mathrm{f}}\right)$ for the standard and new samples are 0.106 and 0.175 respectively. 


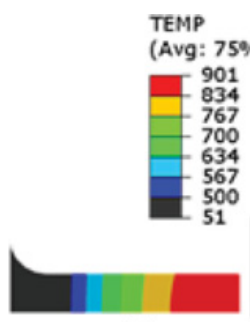

(a)

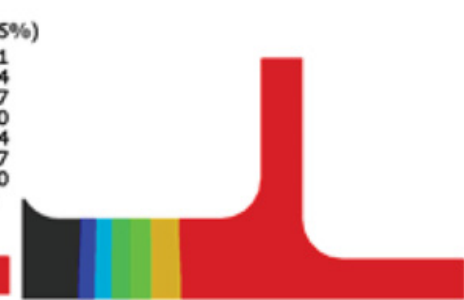

(b)

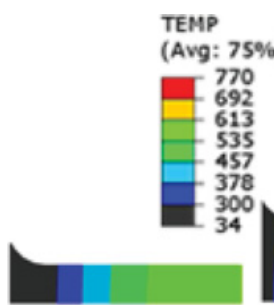

(a) (b)

Figure 5. Temperature fields during soaking.

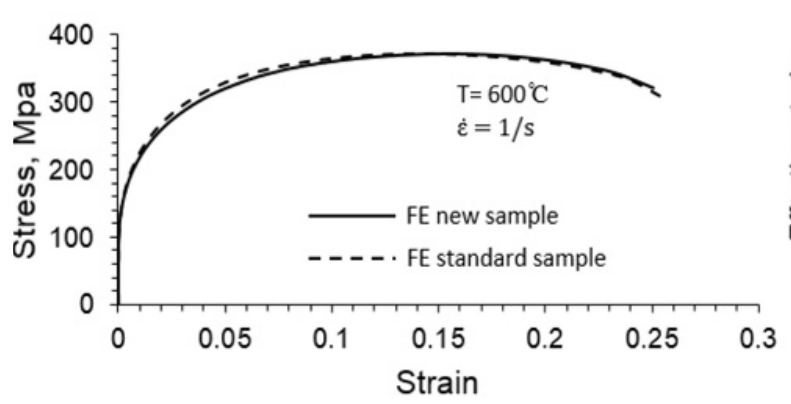

(a)
Figure 6. Temperature fields at the onset of deformation for a) the standard sample and b) the new sample.

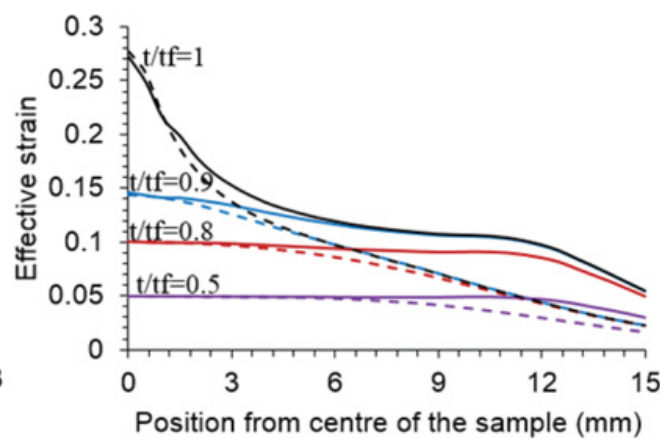

(b)

Figure 7. Comparison of the FE results obtained from the standard (dash) and the new (solid curves) samples. a) Stress-Strain relationships; b) strain distributions along the gauge length.

For a strain level of $0.1\left(t / t_{f}=0.8\right)$, homogenous deformation is observed only up to $3 \mathrm{~mm}$ from the centre of the specimen for the standard specimen, but in the case of new sample it is up to $12 \mathrm{~mm}$ from the centre of the specimen. Since the temperature gradient in the standard sample geometry is large, it leads to large strain gradient over the gauge length. But in case of the new sample geometry, the strain distribution is uniform. This is due to the homogenous temperature during heating and after cooling. It shows that the effective gauge length is $6 \mathrm{~mm}$ in a standard specimen and $24 \mathrm{~mm}$ in the case of the new sample.

\section{Conclusions}

In the present study, the influence of tensile testpiece geometry on temperature gradient and its effect on material deformation was studied in detail. Two kinds of sample designs, a standard dog-bone shape and a newly proposed specimen geometry, were investigated experimentally and numerically. An integrated FE simulation process has been established for the coupled electrical, thermal and viscoplastic deformation analysis. The numerical procedure has been validated from experimental data. It has been concluded that the new specimen design could be used to obtain more uniform temperature over the gauge length, and thus obtain more uniform strain distribution over the specimen gauge length for the material deforming at hot stamping test conditions.

The authors would like to thank Tata Steel for financial support provided for this project. Authors also likes to acknowledge Dr Arunansu Haldar and Mr Peter van Liempt of Tata Steel for their valuable suggestions. 


\section{ICNFT 2015}

\section{References}

[1] N. Li., C. Sun, N. Guo, M. Momhamed, J. Lin and M. Takeki, "Damage Investigation of Boron Steel at Hot Stamping Conditions". Procedia Engineering 81: 1744-1749 (2014)

[2] M. Abspoel, N. Bas M.P. van Liempt, "Exploring process and material parameters for hot forming." 7th Forming Technology Forum ,University of Twente, the Netherlands (2014)

[3] J. Lin., B. Cheong, X. Yao, "Universal multi-objective function for optimising superplastic-damage constitutive equations.” Journal of Materials Processing Technology 125-126: 199-205 (2002)

[4] R. Pandi. and S. Yue. "Dynamic Transformation of Austenite to Ferrite in Low Carbon Steel". ISIJ International 34(3): 270-279 (1994)

[5] http://www.mace.manchester.ac.uk/project/research/structures/strucfire/ materialInFire/Steel

[6] E. Kardoulaki, J. Lin, D. Balint, D. Farrugia,"Investigation of the effects of thermal gradients present in Gleeble high-temperature tensile tests on the strain state for free cutting steel". The Journal of Strain Analysis for Engineering Design 49(7): 521-532 (2014) 